\title{
TRANSFERÊNCIA PRODUTIVA, TEORIA DA DEPENDÊNCIA E FLYING GEESE: A ÁFRICA NA REALOCAÇÃO CHINESA ${ }^{1}$
}

\author{
PRODUCTION TRANSFER, DEPENDENCE THEORY AND FLYING GEESE: \\ AFRICA IN CHINESE RELOCATION
}

DOI: $10.5380 / c g . v 9 i 2.74480$

Bráulio Castillo

Andrea Pacheco Pacifico3

Ana Paula Maielo Silva4

\begin{abstract}
Resumo
Este artigo analisa o recente movimento de realocação industrial chinesa em direção à África. Esse fenômeno possui duas visões distintas quanto à eficácia em produzir desenvolvimento econômico. Os teóricos do Flying Geese Pattern of Development, em tradução livre, modelo de desenvolvimento do voo de gansos, sustentam que a transferência produtiva é catalisadora de desenvolvimento econômico. Já os defensores da "Teoria da Dependência" denunciam que a industrialização guiada por transferência industrial do centro para a periferia é uma das causas da perpetuação do subdesenvolvimento. Dito isso, esse artigo analisa até que ponto alguma dessas teorias é capaz de explicar o lugar da África na transferência industrial chinesa, utilizando uma abordagem qualitativa para inferir em qual realidade material se encontram os países da África atualmente. $\mathrm{O}$ modelo de análise proposto para construir inferências contém duas perguntas, cada uma com duas hipóteses, dentre as quais, uma corresponde ao caminho do subdesenvolvimento, segundo a Teoria da Dependência, e outra ao processo de desenvolvimento do modelo Flying Geese Pattern. Os resultados sugerem que os países analisados respondem positivamente a uma hipótese que leva à dependência, enquanto confirmam que outra atende às condições de desenvolvimento do Flying Geese Pattern. O artigo conclui que os países que albergaram as SEZs chinesas se encontram numa encruzilhada entre decolar a economia e estagnar o subdesenvolvimento. Essa inferência é apoiada pela constatação que, enquanto estes países voltam a produção para a exportação, não obrigam a participação de capital nacional para absorção de tecnologia.
\end{abstract}

Palavras-Chave: Relações China-África; Transferência produtiva; Flying Geese Pattern; Teoria da Dependência.

\footnotetext{
${ }^{1}$ Informações de financiamento.

${ }^{2}$ Mestre em Relações Internacionais pela Universidade Estadual da Paraíba e Bacharel em Direito pela Universidade do Estado do Rio Grande do Norte. E-mail: brauliodutra@gmail.com. ORCID: https://orcid.org/o000-0003-2545-428X.

3 Professora do Programa de Pós-Graduação em Relações Internacionais da Universidade Estadual da Paraíba e Bolsista de Produtividade em Pesquisa nível 2 do CNPq (desde 2019). Pós-doutora em Direito Internacional dos Refugiados pela Universidade de York, Canadá (2009/2010); doutora (PhD), com distinção, em Ciências Sociais pela PUC/São Paulo (2008), com período sanduiche no Center for Refugee Studies da Universidade de York, Canadá; Mestre (LLM/MA) em Direito Internacional e Política/Relações Internacionais pela Universidade de Lancaster, Inglaterra (1999); e bacharela em Direito pela UFAL (1993). E-mail: apacifico@ccbsa.uepb.edu.br. ORCID: https://orcid.org/o0oo-0002-2744-7166.

4 Professora Adjunta do Departamento de Relações Internacionais e do Programa de Pós-Graduação em Relações Internacionais da Universidade Estadual da Paraíba. Atualmente é Professora Visitante na Macquarie University. Doutora em Ciência Política pela Universidade Estadual de Campinas (UNICAMP); Pesquisadora Visitante e Doutorado Sanduíche no Centro para Estudos de Segurança Internacional na Universidade de Sidney, Austrália; Mestre em Relações Internacionais pelo Programa San Tiago Dantas; e Bacharel em Relações Internacionais pela Pontifícia Universidade Católica de Minas Gerais. E-mail: apmaielo@gmail.com. ORCID: https://orcid.org/0000-0003-3790-4305.
} 


\begin{abstract}
This article analyzes the recent Chinese industrial relocation movement towards Africa. This premise has at least two different approaches regarding the effectiveness in producing economic development. Flying Geese Pattern of Development Theory maintains that the productive transfer is catalyst of economic development. "Dependency Theory", on the other hand, denounces that industrialization guided by industrial transfer from the center to the periphery is one of the causes of the perpetuation of underdevelopment. In this sense, this article analyzes to what extent any of these theories have the capacity to explain Africa's place in Chinese industrial transfer, using a qualitative approach to infer in which material reality African countries are currently in terms of productive transfer. The analysis model proposed to build inferences contains two questions, each with two hypotheses, among which, one corresponds to the path of underdevelopment, according to the Dependency Theory, and the other to the process of development from the Flying Geese Pattern model. The results indicate that the analyzed countries respond positively to a hypothesis that leads to dependence, while confirming that another one meets the conditions of development of the Flying Geese Pattern. The work concludes that the countries wich hosted the Chinese SEZs are at a crossroads between taking off the economy and stagnating underdevelopment. This inference is supported by the findings that shows while these countries return production to export, on the other hand they do not require the participation of national capital to absorb technology.
\end{abstract}

Keywords: China-Africa relations; Production transfer; Flying Geese Pattern; Dependency Theory.

\title{
1. INTRODUÇÃO
}

Na virada do século XX para o atual, a China emergiu como potência econômica após as reformas de abertura ao mundo empreendidas por Deng Xiaoping. Com um PIB rondando os 11 trilhões de dólares, em 2015, a República Popular da China (R.P.C.) ganhou o status de segunda maior economia do planeta (LI, 2017, p. 21). Um dos efeitos mais patentes da evolução chinesa foi o surgimento de um parque industrial robusto e diversificado. Como consequência do modelo industrial, existe uma dupla implicação: a procura por novos fornecedores de matérias-primas e a busca de mercados consumidores para os produtos chineses. Foi no contexto dessa dupla imposição à política externa chinesa que a África surgiu como um parceiro ideal. A vasta disponibilidade de produtos primários aliada à existência de um mercado com demanda potencial - estimado em um bilhão de pessoas -, colocaram a África como uma das prioridades da política externa da China (EISENMAN; SHINN, 2018, p. 839).

O comércio entre ambos cresceu meteoricamente nas últimas décadas: de U\$ 10,5 bilhões em 2000 para U\$ 40 bilhões em meados do ano de 2005, chegando a U\$ 166 bilhões em 2011. Já em 2012, a China ultrapassou os Estados Unidos e se tornou o maior parceiro comercial da África (LAHTINEN, 2018, p. 5), embora haja quem afirme que este posto foi tomado pela China desde 2009 (IGHOBOR, 2013). Em 2013, a parceria comercial seguiu crescendo e alcançou os U\$ 210 bilhões, chegando aos U\$ 300 bilhões em 2015 (LAHTINEN, 2018, p. 41). Os Investimentos Diretos Externo chineses na África saltaram de U\$ 1 bilhão em 2000 para U\$ 68 bilhões em 2010 (KOBYLINSKI, 2012, p. 3). A ajuda econômica oferecida pela China aos países africanos aumentou rapidamente: 
partindo de U\$ 5 bilhões em 2006 até atingir U\$ 20 bilhões em 2012 (OBAMBA, 2017, p. 163), chegando aos U\$ 60 bilhões em 2015 (EISENMAN; SHINN, 2018, p. 844).

É latente o crescimento do número de produções acadêmico-científicas que, motivadas pela assimetria característica das relações comerciais, questionam os benefícios que a relação com a China traz para os países africanos (LAHTINEN, 2018, p. 5-6). Os principais argumentos dos críticos da relação sino-africana tocam no modelo de comércio existente. Aproximadamente $85 \%$ das importações chinesas vindas da África são de matérias-primas, tais como petróleo, minério e madeira, ao passo que as exportações para o continente são, principalmente, produtos manufaturados - modelo que guardaria semelhanças com o sistema colonial de exploração (EISENMAN; SHINN, 2018, p. 839).

É inegável que a relação comercial China-África reproduz um clássico padrão de comércio: produtos primários e commodities de um lado (África); produtos manufaturados de valor agregado do outro (China). Apesar de mudarem os atores em cena, a estrutura de comércio global se mantém intacta, neste caso. O comércio e os investimentos chineses na África não são diferentes do padrão aplicado na maioria das parcerias entre outros países ou em outras épocas (MELBER, 2008, p. 394).

Na primeira metade do século XX, saliente-se, a América Latina vivia panorama semelhante ao da África do século XXI, cenário que levara Raúl Prebisch, economista argentino vinculado à Comissão Econômica para a América Latina (CEPAL), órgão ligado à ONU, a desenvolver o conceito de deterioração dos termos de intercâmbio. Seu texto seminal, "El desarollo economico de la America Latina y algunos de sus principales problemas", de 1949, denunciava que a relação econômica centro-periferia (o centro exportava produtos manufaturados e comprava commodities da periferia, cuja dinâmica era inversa: importava manufaturas e exportava matérias-primas) petrificava o subdesenvolvimento na periferia (PREBISCH, 1986). O principal ponto do construto de Prebisch era que as commodities não subiam de preço tanto quanto os manufaturados. Essa conjuntura forçava, ao longo do tempo, intercâmbio comercial cada vez mais vantajoso para o Centro, tanto quanto menos para a Periferia, cuja única alternativa para o desenvolvimento econômico seria começar a industrialização da economia (PREBISCH, 1986).

Diante dessa realidade, a África tem-se tornado destino de investimentos chineses para levantamento de unidades de manufatura. Essa inflexão começa a partir de 2005, quando os chineses começaram a transferir parte de suas unidades produtivas para o exterior. Este movimento foi influenciado pelo aumento gradativo do custo de produção em território chinês, causado, principalmente, pela elevação dos salários médios, pela valorização cambial da moeda chinesa e pelo incentivo do governo chinês para tornar as firmas chinesas forças globais. Com o anúncio do governo chinês, feito em 2015, que incentivaria e fomentaria a cooperação industrial com a África, o continente passou a receber uma parte dessa relocação industrial de origem chinesa (BRAUTIGAM; XIAOYANG; XIA, 2018, p. 30) 
Esse movimento de transferência de unidades produtivas de um país avançado para países menos desenvolvidos foi denominado Flying geese pattern, em tradução livre, "padrão do voo dos gansos". O termo foi cunhado por Kaname Akamatsu, em 1930, para descrever o modelo que o Japão estava empreendendo na sua matriz produtiva, levando parte de sua indústria para o solo de países do Leste Asiático. Nesse modelo, o país líder é a força motriz e vértice de um "V" invertido, cujos flancos são ocupados pelos países menos desenvolvidos, tal qual o padrão adotado por uma revoada de gansos (KOJIMA, 2000).

Os pressupostos que permitem que o modelo de desenvolvimento do flying geese seja posto em prática são: (1) um rápido incremento de tecnologia e do valor agregado da produção nacional, que força um país a transferir para outros países a produção menos rentável ou de tecnologia em desuso; e (2) a busca por vantagens comparativas, tais quais um custo mão de obra mais barata para a produção de gêneros intensivos em mão-de-obra (MEN; BARTON, 2011, p. 78). Akamatsu (1962) sustenta que os países podem ser líderes ou seguidores, conforme suas capacidades, custos e estágio tecnológico da produção. Segundo os defensores da teoria do Flying geese, essa transferência industrial é capaz de desenvolver a economia dos países receptores, tratando-se, portanto, de uma política de desenvolvimento econômico (AKAMATSU, 1962; KOJIMA, 2000).

Como lembram Brautigam, Xiaoyang e Xia (2018, p. 30), ao longo do tempo, entretanto, as atividades de baixo custo tendem a ficar nos países seguidores, enquanto as de alto valor agregado ficam no país líder. Essa transferência de tecnologia ultrapassada do centro para a periferia é um dos principais motes para a escola da Teoria da Dependência. Marini (2000, p. 145) atesta que, na nova divisão internacional do trabalho, são transferidos para os países dependentes as etapas inferiores da produção industrial, reservando-se para as economias centrais as etapas mais avançadas e lucrativas. A dependência, segundo Santos (1970), é uma situação na qual as economias de um grupo de países são condicionadas pelo desenvolvimento e pela expansão de outros. Uma relação entre duas ou mais economias ou entre estas e o sistema de comércio mundial se torna uma relação dependente quando alguns países podem expandir-se por meio de auto impulso, enquanto outros, estando em uma posição de dependência, somente podem expandir como um reflexo dos países dominantes.

Ainda, conforme as lições de Santos (1970), o industrialismo não romperia, per si, com a lógica imperialista da exploração, pois ela seria, segundo Marini (2000, p. 80), cúmplice do imperialismo de duas formas: (1) escravizando a periferia por meio de investimentos externos em capital financeiro; ou (2) transferindo tecnologia ultrapassada para as economias satélites. A alocação de tecnologias obsoletas é, para os dependentistas, uma das principais causas da perpetuação do subdesenvolvimento nos países periféricos. Desta monta, na ótica da Teoria da dependência, a industrialização dos países subdesenvolvidos alavancada por transferência produtiva é uma das causas da perpetuação do subdesenvolvimento. 
Diante dessa contraposição teórica, restam alguns questionamentos que esse artigo tentará responder. Afinal, a transferência industrial de um país mais desenvolvido para um país em estágio mais atrasado tende a ser "motor de desenvolvimento", como dizem os adeptos do modelo do Flying Geese Pattern, ou a perpetuar o subdesenvolvimento, tal qual defende a escola da Teoria da Dependência? Respondida esta questão, resta outra: quais as perspectivas dos países africanos frente à iminente transferência produtiva chinesa para o continente?

Para tanto, esse artigo realiza, primeiro, uma breve introdução que contextualiza o problema. Em seguida, faz explanações acerca do movimento de Transferência Produtiva. Em ato contínuo, o trabalho traz as conexões entre a Transferência produtiva e a Teoria da Dependência - para, depois, concatenar a teoria de desenvolvimento do Flying Geese Pattern com a Transferência industrial. Por fim, o artigo se debruça sobre a análise qualitativa para tentar inferir em qual dos dois cenários teóricos se encaixam os países da África, criando um modelo qualitativo para gerar inferências relevantes sobre o objeto, antes de tecer as considerações finais.

\section{REALOCAÇÃO INDUSTRIAL: MOTOR DE DESENVOLVIMENTO OU PERPETUAÇÃO DO SUBDESENVOLVIMENTO?}

A ordem internacional de produção industrial tem sido substancialmente modificada desde a segunda metade do século XX. Guiado pela liberalização comercial, pelo barateamento dos transportes e pela diminuição dos custos de comunicação, o mundo tem testemunhando uma realocação da produção industrial internacional. Esse processo tem transferido indústrias de países com altos salários para economias de baixos salários. Tem-se notado importantes segmentos desta nova ordem de produção internacional transferirem as atividades de manufatura para países em desenvolvimento, pois esses possuem as vantagens competitivas necessárias às empresas industriais multinacionais, tais como mão-de-obra mais barata do que no país-sede (MORTIMORE, 1993, p. 16).

A Realocação Industrial, também conhecida como Transferência produtiva, Mudança do Arranjo Produtivo, Offshoring, entre outras, representa um dos processos mais visíveis da Globalização. A suavização das barreiras alfandegárias e econômicas dos países, em curso desde a década de 1980, potencializou o processo de realocação industrial para países em desenvolvimento. O movimento padrão envolve as empresas multinacionais, que transferem, parcial ou totalmente, a produção de bens desde os países avançados para aqueles subdesenvolvidos, ou em desenvolvimento, com o intuito de obter menores custos de produção. Essa diminuição no custo da produção acarreta em (1) maior lucratividade para a empresa e (2) uma maior competitividade internacional para seus produtos (ANDERSEN, 2006, p. 103). 
Como notou Cantwell (1991, p. 11), a internacionalização da produção pode ser de quatro tipos: (a) guiada pela busca de recursos naturais; (b) focada para empreender a substituição de importações; (c) direcionada como plataforma exportadora; e (d) criada para compor cadeias globais integradas. Não obstante a variedade de tipos, há um fator estrutural que permite a realocação: o progressivo avanço tecnológico da indústria dos países centrais. Isso não significa que os processos e os produtos que possuem tecnologia obsoleta deixam de ser produzidos pelas empresas do Norte global. O que ocorre é a transferência da localização geográfica da produção: os processos são alocados em países subdesenvolvidos, pois estes, em regra, oferecem menores custos para as multinacionais, tais como salários mais baixos. O fio condutor desse processo, portanto, é a substituição da tecnologia nos países centrais, que instalam a tecnologia superada nos países em desenvolvimento.

\section{TRANSFERÊNCIA INDUSTRIAL E A TEORIA DA DEPENDÊNCIA}

Na década de 1940, o pensamento estruturalista (identificado com a CEPAL) denunciava que países agroexportadores estariam fadados à eterna posição periférica, pois não teriam ferramentas para avançar tecnologicamente sua economia e, por isso, não seriam capazes de ter autonomia nacional. Como apontou Mello (1988, p. 15), "as economias periféricas enquanto exportadoras de produtos primários não dispõem, assim, de comando sobre seu próprio crescimento que, ao contrário, depende, em última instância, do vigor da demanda cêntrica”.

O desequilíbrio na balança de pagamentos dos países latino-americanos, provocado pelo modelo de exportação de produtos agrícolas e importação de bens manufaturados, foi o cerne principal da crítica cepalina ao comércio centro-periferia. Prebisch, em texto publicado em 1949, intitulado "El desarollo economico de la America Latina y algunos de sus principales problemas", concebeu a gênese do pensamento da CEPAL, defendendo a industrialização, por meio do processo de substituição de importações, como caminho certo para os países da região atingirem o desenvolvimento (PREBISCH, 1986). Esse construto teórico, portanto, via a industrialização como a prima ratio para se alcançar a autonomia nacional e o seu desenvolvimento econômico subjacente.

Apoiados em políticas industriais, o México e o Brasil puseram em prática os conselhos de Prebisch e empreenderam certa industrialização da economia até meados do século XX. Houve um avanço significativo na industrialização, de tal maneira, que foi viabilizada a infraestrutura necessária para substituir parte considerável das importações (HAGE, 2013, p. 118). Esse processo de implantação industrial, entretanto, não foi endógeno. Os países latino-americanos receberam robustos e significativos investimentos externos. Grande parte das inversões se traduziram em transferência de parte da produção, vinda dos países do Norte. Isto é: a industrialização latinoamericana ocorreu substancialmente por meio da transferência industrial. 
Os conselhos cepalinos, entretanto, não trouxeram os frutos esperados. Apesar de conseguir formar capacidades industriais, os países da América Latina não gozaram do desenvolvimento econômico esperado. Viu-se, em meados dos anos 1960, a reprodução de graves distorções sociais, bem como a conservação do distanciamento entre o Norte e o Sul globais (HAGE, 2013, p. 118). A industrialização foi conseguida, mas o subdesenvolvimento persistia. A partir dessa constatação, a Teoria da Dependência vai tecer análises acerca do processo de industrialização e apontará fatores qualitativos, tais como a limitada tecnologia industrial transferida e a insuficiência do processo de substituição de importações, como causas do fracasso do processo de industrialização da região.

A formação de uma indústria galgada na realocação produtiva dos países centrais, voltada para a produção de mercadorias para substituição de importações, explica o fracasso do processo industrial da região, segundo os teóricos da Dependência. Como explicita Marini (2000, p. 80), o industrialismo não rompe com a lógica de exploração capitalista, pois o imperialismo é compatível com a industrialização nacional, quando esta é guiada por transferência de tecnologia ultrapassada.

Segundo Marini (2000), portanto, a tecnologia ultrapassada, emperra o desenvolvimento industrial de um país porque: (1) o produto não terá a mesma tecnologia daquele vindo do país-líder do segmento; (2) a matriz produtiva nacional não terá capacidade de competir com os arranjos produtivos mais tecnológicos pelo mercado internacional; (3) a incapacidade de competição internacional relega o produto nacional a alimentar somente o mercado interno, que, não raro, exigirá imposição de barreiras contra a importação; e (4) os poucos excedentes não são suficientes para investir em tecnologia produtiva de ponta.

Dessa forma, a realocação industrial sem progresso tecnológico, servirá somente para a substituição de importações. Esta, por sua vez, não tem capacidade de modificar as estruturas econômicas do país receptor, pois somente transforma superficialmente a matriz econômica, substituindo a economia colonial pelo paradigma industrial, sendo incapaz de desenvolver sistemas econômicos com desenvolvimento autônomo e, por isso, provoca estagnação na economia nacional, pois é incapaz de avançar aos estágios tecnológicos de produção que os países centrais possuem (FURTADO, 1968, p. 38-39).

No panorama de substituição de importações, a economia nacional recebe, ainda que tímidos, certos avanços, pois o país recebe novos processos, instituições e culturas industriais de países mais avançados. Entretanto, as amarras da dependência persistem por meios mais implícitos. Devido à grande necessidade de capital das multinacionais, não existe cultura de formação e acumulação de capital nacional. As decisões estratégicas, o planejamento industrial, a criação de produtos e Pesquisa \& Desenvolvimento (P\&D) ficam alocados geograficamente no país sede da empresa, cabendo ao Estado receptor, produzir conforme a estrita necessidade da matriz (HAGE, 2013, p. 123).

A transferência industrial, portanto, pode não somente falhar em produzir desenvolvimento econômico nacional, mas ela também pode ser um fator determinante na perpetuação do atraso e do 
subdesenvolvimento econômico. Foi o que aconteceu com a indústria de bens e consumo duráveis no Brasil, por exemplo, segundo Furtado (1981, p. 128), onde se desenvolveu um parque com dimensão global e com economia de escala, mas sofreu pela impossibilidade de produzir o maquinário (bens de capital) no país, o que expõe o sistema industrial do país ao desequilíbrio: moderno tecnicamente, mas incapaz de desenvolver a economia nacional.

O processo de industrialização da América Latina não foi acompanhado por um desenvolvimento econômico dos países da região como esperavam os estruturalistas da CEPAL. Os construtos teóricos da Teoria da Dependência justificam essa falha tanto porque a tecnologia empregada era concebida pela matriz, como também pela obsolescência comparativa: os processos já eram ultrapassados, incapazes de competir com a técnica dos países industrializados do Centro. Assim sendo, a Europa Ocidental e os EUA sempre guardavam uma vantagem considerável sobre os novos países em processo de industrialização (HAGE, 2013, p. 123).

Diante do exposto, pode-se inferir, portanto, que o movimento de dispersão da indústria do Norte em direção ao Sul global é uma realidade desde meados do século XX. O processo de industrialização levado a cabo pelos países latino-americanos, como Brasil, Argentina e México, por exemplo, foi galgado, mormente, por meio do processo de transferência industrial. Entretanto, como mostram os construtos da Teoria da Dependência, essa transformação de economia agrícola em economia industrial não trouxe junto o desenvolvimento econômico esperado, como prediziam os estruturalistas da CEPAL.

Com a ajuda da escola da Teoria da Dependência, pode-se identificar quando um processo de transferência industrial é maléfico para o país receptor. Para os dependentistas, sempre que a realocação produtiva instalar (1) um parque industrial com tecnologia ultrapassada, para (2) produzir gêneros voltados para substituir importações, esse processo não será capaz de gerar desenvolvimento econômico para o país receptor. Pelo contrário: esse panorama é um catalizador de subdesenvolvimento, pois somente reproduz o padrão de exploração centro-periferia. Nesse arranjo, a transferência industrial pode ser uma armadilha, pois caberá ao Centro fabricar o produto de alto valor agregado (alta tecnologia embarcada), e à Periferia, somente produtos intensivos em mão-deobra (com tecnologia obsoleta ou incapaz de concorrer no mercado internacional com o Centro).

\section{TRANSFERÊNCIA INDUSTRIAL E O 'FLYING GEESE PATTERN'}

A expressão "flying geese pattern of development", em tradução livre, "Padrão de desenvolvimento do voo de gansos", foi cunhada originalmente por Kaname Akamatsu nos anos 1930, em artigos escritos em japonês, mas impedidos de serem publicados na Academia internacional devido à Segunda Guerra. Somente no início da década de 1960, os escritos foram publicados em inglês (KOJIMA, 2000, P. 376). 
A objetivo central da teoria do Flying Geese é tentar explicar o processo de decolagem industrial das economias "retardatárias" e seu objeto de análise, para elaborar a teoria do Flying Geese, foi o processo de industrialização do Japão e sua consequente transferência industrial empreendida em direção aos países do Leste Asiático, a partir do período pós-Guerra. O nome escolhido deriva da observação de uma revoada de gansos selvagens, que se dispõem de maneira similar a uma ponta de lança, com um ganso líder ao centro e duas filas nos flancos.

Segundo Akamatsu (1962), esse padrão simbolizava exatamente o processo de industrialização do Leste Asiático, pois ao centro, o ganso líder seria o Japão e os gansos nas alas seriam os países receptores de "transferência industrial", cuja distância para o líder denotaria o estágio de desenvolvimento: quanto mais se desenvolvia, mais perto chegava do ganso líder. A Figura 1 abaixo demonstra a disposição dos países no referido modelo

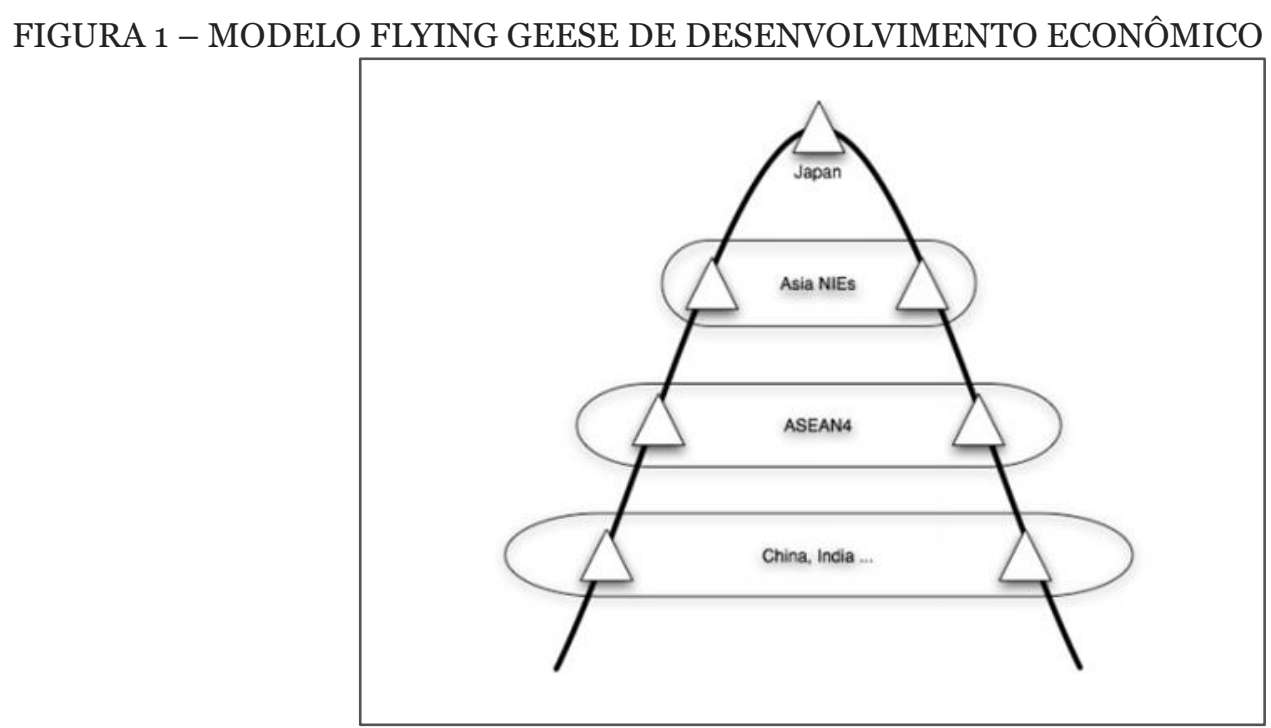

Fonte: Kumagai (2008, p. 04).

Como a Figura 1 mostra, essas eram as posições dos países no início do processo percebido. As novas economias industrializadas, ou simplesmente "Tigres Asiáticos”, eram Taiwan, Hong Kong, Coreia do Sul e Singapura. A Associação das Nações do Sudeste Asiático (ASEAN) é formada por Malásia, Tailândia, Filipinas e Indonésia. Por último, cita-se os 'retardatários' do processo, tais como China, Índia e Vietnam. Quanto mais acima estão posicionados, maior era seu estágio de desenvolvimento econômico-industrial (OKITA, 1985). Segundo Kojima (2000), a arrancada industrial de um país subdesenvolvido ocorre quando (1) a indústria nacional cresce, gerando aumentos sucessivos nas curvas de importação, produção e exportação, respectivamente; e (2) a base industrial nacional se diversifica e passa a produzir bens mais sofisticados (tais como bens de capital) em vez de produtos básicos, como bens de consumo. Este é o primeiro pilar do Flying Geese Pattern (KOJIMA, 2000, p. 376). A Figura 2 exemplifica o comportamento econômico do país receptor no modelo de desenvolvimento em questão e a Figura 3 exemplifica a estruturação da produção de bens no Leste Asiático. 
Volume of

(1) imports

(2) production

(3) exports

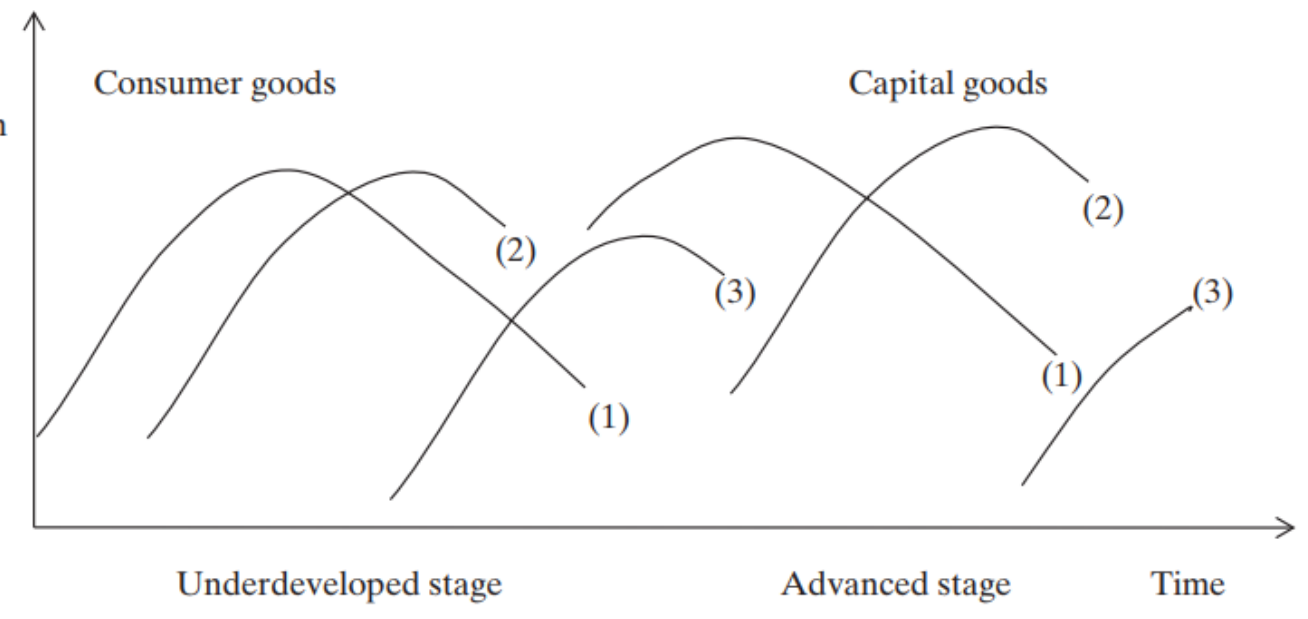

Fonte: Kiyota (2014, p. 178).

FIGURA 3 - TRANSFORMAÇÃO NA ESTRUTURA PRODUTIVA DE BENS NO LESTE ASIÁTICO, SOB A PERSPECTIVA DO FLYING GEESE PATTERN

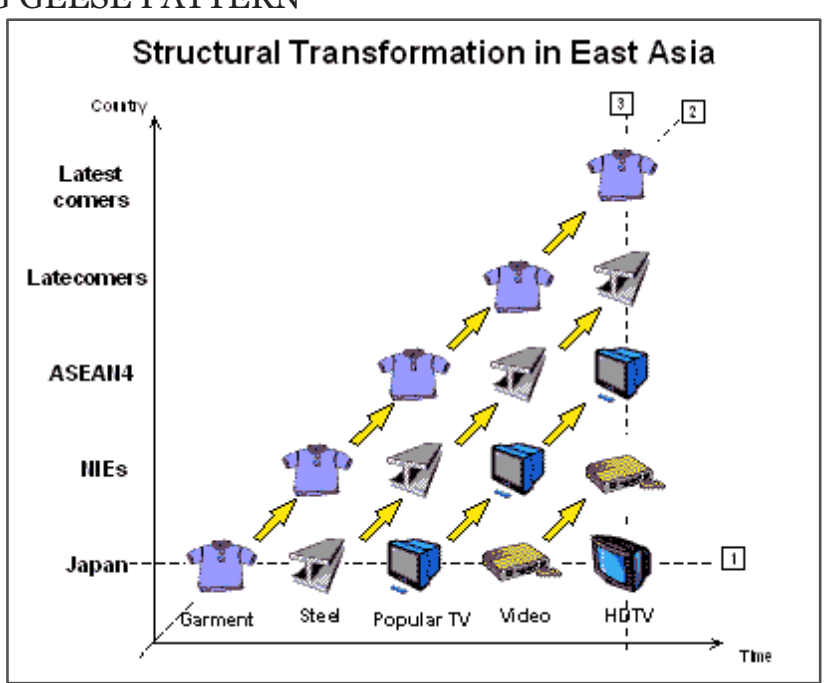

Fonte: GRIPS (2002).

A transferência industrial regionalizada tem como núcleo central o Investimento Externo Direto (IED) direcionado para o comércio - esse é o segundo pilar teórico -, tal mecanismo, portanto, significa que quando um ambiente produtivo de um país investidor se torna desvantajoso, a produção é transplantada para outro país que abarque vantagens comparativas melhores do que no primeiro. O terceiro pilar teórico é a especialização combinada, isto é, os países receptores organizam um arranjo produtivo para não rivalizar os processos industriais, permitindo cada um deles tomar a dianteira em um processo específico e aumentando o comércio intraindústrias (KOJIMA, 2000, P. 376).

O processo completo de desenvolvimento econômico, por meio do Flying Geese, se dá por meio de quatro etapas, segundo os ensinamentos de Akamatsu (1961, 1962): 
Estágio 1: quando uma nação subdesenvolvida entra no comércio mundial, exporta commodities e produtos primários e importa, das nações desenvolvidas, produtos manufaturados para consumo interno.

Estágio 2: quando a indústria doméstica do país em desenvolvimento inicia a produção dos bens de consumo que eram importados anteriormente, enquanto importa, agora, bens de capital, isto é, maquinário e meios de produção para produzir esses bens do processo de substituição de importações.

Estágio 3: quando o país em desenvolvimento começa a exportar bens de consumo manufaturados e, simultaneamente, a indústria de maquinaria e bens de capital começa a florescer, razão pela qual os as importações de bens de capital começam a declinar.

Estágio 4: quando a indústria de bens de consumo do país em desenvolvimento alcança um estágio similar ao dos países avançados e, consequentemente, a exportação de bens de consumo começa a diminuir, ao passo que os bens de capital usados na produção daqueles bens de consumo começam a ser exportados.

No momento em que o país atinge o estágio 4, a ordenação deles se dá pelo nível de avanço tecnológico-industrial. O "ganso" menos desenvolvido persegue aquele que está à sua frente e, assim, sucessivamente, seguindo o caminho que o "ganso" líder percorreu para seu desenvolvimento; os "gansos" mais avançados inovam incessantemente sua planta industrial a fim de se manter à dianteira dos menos avançados (AKAMATSU, 1962, p. 17-18).

No geral, pode-se observar uma diferença abismal entre o processo de industrialização do Leste Asiático e da América Latina, desde meados do século XX. Enquanto a industrialização latinoamericana não forneceu o desenvolvimento econômico esperado, no Leste de Ásia, o modelo de transferência industrial protagonizado pelo Japão conseguiu entregar um desenvolvimento industrial, econômico e social consideráveis aos países que receberam aportes. Se nos anos 1960, o Japão era o único país desenvolvido da Ásia, hoje, na América Latina, é muito comum dirigir carros coreanos ou falar através de celulares chineses.

Pode-se elencar os motivos pelos quais o processo de transferência produtiva do Japão para o Leste Asiático foi exitoso, diferentemente do latino-americano: (1) enquanto na América Latina a produção foi orientada, mormente, para a substituição de importações, no modelo Flying Gesse, os investimentos produtivos foram direcionados para a exportação. Sendo assim, (2) as indústrias do Leste Asiático não poderiam abarcar tecnologia obsoleta ou ultrapassada por completo, pois, assim fosse, o produto perderia competitividade internacional, razão pela qual, a tecnologia recebida proporcionava um razoável e constante avanço técnico da indústria nacional, que, consequentemente, (3) conseguia produzir bens de capital, muito mais lucrativos que bens de consumo.

Conclui-se, segundo a ótica do Flying Geese Pattern, que a industrialização da América Latina não passou do Estágio 2 descrito por Akamatsu (1961, 1962). As economias latinas receberam 
transferência produtiva vinda dos países centrais, particularmente Europa Ocidental e Estados Unidos, mas voltaram a sua produção somente para substituição de importações, não atingindo os Estágios 3 e 4 (FURTADO, 1968, p. 38-39), isto é, não conseguiram produzir maquinário e bens de capital para fabricar os bens de consumo da substituição de importações. Logo, a América Latina ficou dependente dos investimentos externos produtivos, que chegavam por meio de transferência industrial, via de regra, com tecnologia obsoleta, que não permitiam que os bens de consumo fabricados na região competissem internacionalmente, restando, para esses, preencher a lacuna de substituir os produtos que antes eram importados dos países desenvolvidos para abastecer os mercados domésticos.

A partir do exposto, resta analisar as predileções em curso do movimento de transferência industrial chinesa para a África. A realocação chinesa no continente tende a gerar desenvolvimento econômico, como predizem os teóricos do Flying Geese Pattern, igual ao que foi proporcionado pelo Japão no Leste Asiático? Ou o movimento de implantação da capacidade industrial guiada pela China manterá os países do continente no subdesenvolvimento e dependência, como denuncia a Teoria da Dependência, tal qual ocorreu com a América Latina?

\section{OS GANSOS AFRICANOS PODEM VOAR?}

Com um rápido avanço econômico, a indústria chinesa tem-se modernizado bastante, desde seu impulso inicial dos anos 1980. Hodiernamente, a indústria pesada, química e de maquinaria (bens de capital) tem ocupado boa parte do arranjo industrial doméstico. Isso explica o motivo pelo qual as empresas chinesas intensivas em mão-de-obra estão migrando para o exterior, em busca das vantagens comparativas corroídas da década de 1980 para cá. O estrangulamento da mão-de-obra excedente, o aumento dos salários dos trabalhadores e a valorização cambial forçam a China a realocar sua produção, principalmente a de baixo valor agregado, intensiva em mão-de-obra (MEN, BARTON, 2011, p. 73).

O governo chinês tem encorajado firmas nacionais a investirem no exterior, mormente em países em desenvolvimento. O Investimento Externo Direito (IED) chinês na África saiu de U\$ 16 bilhões em 2011 para 34 bilhões em 2015, com o setor de manufatura aparecendo em primeiro lugar: 44,5\% do IED chinês vai para esse setor (XIAOYANG, 2018, p. 01-02). Há a esperança de que pelo menos 10\% das atividades industriais chinesas de baixo valor agregado (intensiva em mão-de-obra) sejam transplantadas para a África, o que geraria 16 milhões de empregos instantaneamente (OZAWZA; BELLAK, 2011, p. 03).

Saliente-se que há um longevo e histórico envolvimento chinês na industrialização africana, tanto por projetos de Ajuda Externa, quanto por Investimento Externo Direto (SONG, 2011). Ainda na década de 1960, há o registro de empresas chinesas investindo em manufatura na Nigéria, em 
busca de produzir utensílios de cozinha, sandálias de plástico e material de construção (SONG, 2011). No início dos anos 1990, uma companhia têxtil chinesa ergueu uma fábrica nas Ilhas Maurício para exportar à União Europeia. Em 1999, o mercado de televisores em preto-e-branco na África do Sul era dominado por produtos montados localmente por uma firma chinesa, a Shangai Guangdian Company (WANG, 2002). Segundo a UNCTAD (2007), entre 1979 e 2000, empresas chinesas já tinham estabelecido 230 fábricas na África. Esses investimentos aceleraram após a virada do milênio. Em 2005, 45\% das empresas chinesas que planejavam investir no exterior tinham a intenção de erguer fábricas na África (BATTAT, 2006)

A tentativa de industrialização africana acontece desde os anos 1950 e se intensificou após o surgimento de vários países independentes na década de 1960 (MENDES et al. 2014, p. 120). Esses primeiros impulsos foram majoritariamente liderados por políticas econômicas estatais, que visavam introduzir a substituição de importações, a exemplo do que ocorria concomitantemente com o Brasil e o México, mas falharam devido a fatores estruturais, tais como ausência de capital nacional, deficiência de capital humano, baixa qualificação da mão-de-obra, estruturas burocráticas ineficientes, baixo nível de poupança doméstica (o que impede a formação de capital nacional) e depreciação dos termos de troca (baixa nos valores dos produtos que exportava e aumento do preço dos bens que importava) (MENDES et. al., 2014, p. 136). Ainda, segundo Mendes et al. (2014, p. 136), o parque industrial africano era ineficiente, ultrapassado e operava abaixo da capacidade instalada, o que tornava a produção muito custosa e relegou, por exemplo, a África Subsaariana como a região menos industrializada do planeta por volta de 1981.

Inspirados pela emancipação econômica galgada pelos tigres asiáticos por meios das Special Economic Zones (SEZ), esse modelo começou a ser difundido pelos países africanos nos anos 1990 (OLUWASEYI, 2016, p. 32). As SEZs são áreas geográficas delimitadas dentro de um país, nas quais as empresas instaladas desfrutam de uma série de vantagens, tais como concessão de terras, benefícios fiscais, privilégios de financiamento, regimes alfandegários mais liberais, normas trabalhistas flexíveis e infraestrutura hídrica, energética e logística, cujo foco produtivo é a manufatura voltada para a exportação (ZENG, 2019).

A China, por meio do seu Ministério do Comércio (MOFCOM), aprofundou o conceito de SEZ e criou as chamadas Overseas Economic and Commercial Cooperation Zones (OECCZ), destinadas a abrigar enclaves chineses em territórios estrangeiros nos quais haja vantagens econômicas para a instalação de indústrias chinesas (PAIRAULT, 2018, p. 4). Atualmente, o MOFCOM certificou 20 zonas que ostentam esse título, dentre as quais, quatro na África: Zâmbia, Etiópia, Nigéria e Egito (MOFCOM, 2020).

Embora haja, claramente, um movimento no qual empresas chinesas estão investindo em fábricas na África, existe uma certa dificuldade em acessar com exatidão o valor e o escopo desses investimentos, pois os vários bancos de dados e pesquisas demonstram valores discrepantes uns dos outros. Por isso, é de valor considerável o trabalho de Brautigam, Xiaoyang e Xia (2018), que 
empreenderam pesquisa de campo em quatro países de baixa renda da África subsaariana (Etiópia, Gana, Nigéria e Tanzânia) e concluíram que existe tanto investimentos produtivos voltados para exportação, até em cadeias globais de valor, quanto existe, também, relocação industrial que mira o mercado interno, principalmente na Nigéria, país mais populoso da África (BRAUTIGAM, XIAOYANG, XIA, 2018, p. 31). Na literatura, é possível encontrar autores defendendo que a África pode desenvolver-se por meio do modelo de transferência industrial chinesa em curso (MEN; BARTON, 2011, p. 73; THORBORG, 2017, p. 72). Sendo assim, resta necessário abordar o cenário de cada um dos países que recebe SEZs chinesas certificadas pelo MOFCOM.

Carmody (2017, p. 873-874) atesta que na SEZ chinesa da Zâmbia, embora mais de U\$ 1 bilhão tenham sido investidos pelo Estado, a maioria das empresas instaladas tinha capital 100\% chinês, somente três eram nacionais (e, ainda assim, dedicadas à extração de cobre); que os lucros da operação eram enviados às sedes das corporações na China; e que o país continua com uma pauta de exportação de produtos primários e importador de produtos industrializados.

Sobre a SEZ chinesa na Etiópia, Fowler (2019, p. 183) atesta que o país oferece isenção de impostos sobre a importação de todo o maquinário chinês, para o qual a finalidade é, primordialmente, a exportação de manufaturados; que a SEZ chinesa não admite instalação de empresas estrangeiras não-chinesas; que não há empresas chinesas em parceria com nacionais e que inexiste transferência de tecnologia para os etíopes.

Na Nigéria, que abriga a SEZ chinesa de Lekki, as empresas ganham incentivos fiscais, privilégios aduaneiros e produzem, majoritariamente, para a exportação; os fabricantes locais são proibidos de operar no perímetro da área, mesmo que elas tenham participação econômica do governo local, fato que faz a realocação industrial ser considerada uma ameaça para o desenvolvimento industrial local (OKERE, 2019).

A SEZ chinesa de Suez, no Egito, apresenta algumas semelhanças e diferenças vis-à-vis a outros projetos. Assemelha-se porque serve como plataforma de exportação para empresas chinesas atenderem o mercado Europeu; diferencia-se porque há uma obrigatoriedade de 90\% da mão-deobra ser de origem local, o que promove a aprendizagem dos processos pela mão-de-obra nacional, e porque, embora não haja obrigatoriedade de participação do capital nacional nos empreendimentos, já é notada uma razoável quantidade de operações nas quais há capital chinês e egípcio envolvidos juntos, o que pode promover a transferência de tecnologia (GADALLAH, 2016, p. 96-99).

O exemplo da SEZ chinesa no Egito poderia representar um modelo capaz de gerar desenvolvimento, pois há a ocorrência de plantas industriais em parceria com o capital local. Entretanto, Gadallah (2016, p. 96) ressalta que as parcerias sino-egípcias são voltadas a atividades de baixa tecnologia, tais como confecção de vestuário e montagem de utilidades domésticas. Além disso, é necessário ressaltar o caso da tentativa de implantação de SEZ chinesa na Argélia, a qual falhou porque o governo argelino exigiu a integração de empresas nacionais no processo de produção 
que a empresa automotiva Jiangling planejava, pleito negado pelos chineses e que resultou no cancelamento da certificação da SEZ no país pelo MOFCOM (PAIRAULT, 2018, p. 5).

Como as evidências empíricas são heterogêneas (BRAUTIGAM, XIAOYANG, XIA, 2018), não há como predizer se o destino dos países africanos que estão recebendo transferência industrial chinesa é único, isto porque a África abriga países com diferentes estágios e culturas econômicas, de modo que seria errôneo tratar do continente de forma homogênea. Ademais, tanto o desenvolvimento, estilo Flying Geese, quanto o subdesenvolvimento, tal qual a Teoria da Dependência, são visíveis a médio e longo prazo. Sendo inócuo, portanto, fazer conclusões perenes acerca dos efeitos de um fenômeno em andamento.

O que a pesquisa científica pode e deve fazer é produzir um método replicável capaz de gerar inferências. Assim sendo, é trivial que o pesquisador, apoiado por sólido suporte teórico, construa um modelo capaz de solucionar problemas em iminência de ocorrer. Seguindo esse diapasão científico, este artigo propõe um modelo com duas perguntas, cada qual com duas hipóteses que pretendem responder se o modelo de transferência empreendido atualmente pode levar o país africano (ou qualquer outro país subdesenvolvido que esteja executando o mesmo processo) a trilhar o caminho da dependência ou do desenvolvimento.

1. A Transferência Produtiva será voltada para atender qual mercado?

Hipótese 1.1: caso o alvo dos investimentos em manufatura seja somente o mercado interno, via substituição de importações, está satisfeita uma das condições que a Teoria da Dependência denuncia como petrificadora do subdesenvolvimento nos países dependentes, tal qual o fenômeno ocorrido com a industrialização dos países latino-americano;

Hipótese 1.2: na hipótese de a alocação industrial ser direcionada para o mercado externo, via plataforma de exportações, há chances reais de incremento do desenvolvimento econômico, segundo a teoria do Flying Geese Pattern, pois essa foi uma das características do modelo de industrialização do Leste da Ásia, que elevou o nível de desenvolvimento econômico dos países da região.

2. Será permitida a instalação de empresa sem participação do capital nacional?

Hipótese 2.1: no caso de ser possível o investimento exclusivamente com capital externo, há pouca chance de haver transferência de tecnologia e know-how ou qualificação da mão-de-obra nacional - panorama que obstrui a possibilidade de arrancada industrial autônoma da economia receptora, como asseguram os construtos da Teoria da Dependência, pois foi isso que ocorreu no cenário da implantação industrial da América Latina, cujos países eram meros hospedeiros de empresas estrangeiras.

Hipótese 2.2: na hipótese de ser obrigatória a participação do capital nacional, aumentam consideravelmente as chances de a indústria nacional assimilar os processos produtivos e assumir para si, a posteriori, a produção daquele bem - cenário que permite o desenvolvimento industrial e econômico -, conforme o esquema proposto pelo Flying Geese Pattern, cujo exemplo claro dessa 
política é a própria China, que obriga a participação de capital nacional em qualquer investimento industrial estrangeiro, meio pelo qual o país consegue acesso às tecnologias contemporâneas e desenvolve o produto nacional.

Assim sendo, se na transferência industrial chinesa para a África, aplicarem-se as hipóteses 1.1 e 2.1, maior é a chance de o cenário tender para a inocuidade de desenvolvimento, tal qual o evidenciado pela América Latina, elegendo a Teoria da Dependência como a autoridade teórica explicativa. Entretanto, caso se apliquem as hipóteses 1.2 e 2.2, maior a tendência de o movimento chinês trazer consigo o desenvolvimento econômico que saborearam os países do Leste Asiático, qualificando, assim, os construtos propostos pela teoria do Flying Geese Pattern of Development.

Pelas evidências que a literatura sugere, é possível inferir que, nos casos observados, (hipótese 1.2) o mercado que as SEZs chinesas na África miram é, primordialmente, o externo, tratando-se, portanto, de uma plataforma de exportação, condição que atende ao pressuposto do Flying Geese Pattern e pode levar o país a produzir bens competitivos no mercado global e trazer desenvolvimento para a economia local; e (hipótese 2.1) é possível a instalação de empresas sem a participação de capital nacional, o que performa, por outro lado, uma condição que tende a petrificar o subdesenvolvimento, segundo a Teoria da Dependência, visto que não há transferência de tecnologia para o empresariado nacional.

Denota-se, portanto, que os países africanos aqui analisados estão no meio caminho entre o Flying Geese e a Teoria da Dependência. Entretanto, são seus próximos passos que determinarão o caminho que tomarão rumo ao desenvolvimento nacional ou à petrificação do subdesenvolvimento. No caso de manter inalterado o cenário atual, é improvável que a economia local decole tal qual as do Leste Asiático, visto que somente servirão como hospedeiros da produção e, portanto, não transformarão a economia local por meio do desenvolvimento de uma indústria nacional. Já para alcançar o desenvolvimento pelo qual passaram os tigres asiáticos, os governos locais haveriam de reformar as estruturas regulatórias a fim de determinar a participação compulsória do capital local, pois, assim, poderia absorver a tecnologia e o know-how industrial e desenvolveria uma planta industrial com o capital nacional.

\section{CONSIDERAÇÕES FINAIS}

Não se deve olvidar que ambos os processos que foram objetos empíricos analíticos (o processo de industrialização do Leste da Ásia para o Flying Geese Pattern; e o da América Latina, para a Teoria da Dependência) ocorreram simultaneamente no tempo (meados do século XX, intensificando-se no pós-Guerras). A conclusão diferente que ambas fazem de um mesmo processo econômico deriva das diferenças que cada um dos objetos estudados apresentou. Enquanto a América Latina emperrou na etapa de substituição de importações como um fim em si mesmo, no 
Leste Asiático, ela foi somente um dos degraus pelos quais os países receptores de transferência industrial tiveram que galgar. Outro fator que divergiu nos dois processos foi a questão da nacionalização dos processos e capitais: enquanto, na América Latina, o território nacional serviu como mero hospedeiro de empresas internacionais, inexistindo transferência de tecnologia para o capital nacional, no Leste Asiático, houve uma política industrial que demandava a participação de capital nacional, cenário que forçava a apropriação de tecnologia e conhecimento industrial.

Ao analisar o cenário no qual a África se encontra diante da transferência industrial chinesa para o continente, os resultados sugerem que os países que albergaram as SEZs chinesas se encontram em uma encruzilhada, pois estão a meio caminho tanto de decolar a economia, no estilo Flying Geese, quanto de estagnar o subdesenvolvimento, conforme a Teoria da Dependência. Isto porque, enquanto voltam a produção para a exportação (como o Leste da Ásia, diferentemente da América Latina), não obrigam a participação de capital nacional para absorção de tecnologia (como a América Latina, diferentemente do Leste da Ásia). Isto significa, portanto, que os próximos passos da política industrial dos países aludidos poderão ditar o rumo do desenvolvimento econômico que irão tomar, devendo, para atingir o desenvolvimento econômico, adotar o estilo Flying Geese, ou seja, adotar a obrigatoriedade de participação do capital nacional junto aos arranjos industriais que estão sendo transferidos para o continente.

*Artigo recebido em 13 de junho de 2020, aprovado em 03 de setembro de 2020.

\section{REFERÊNCIAS}

AKAMATSU, Kaname. A theory of unbalanced growth in the world economy. Weltwirtschaftliches Archiv, v. 86, p. 196-217, 1961.

AKAMATSU, Kaname. Historical pattern of economic growth in developing countries. The Developing Economies, v. 1, p. 3-25, 1962.

ANDERSEN, Paul Houman. Regional Clusters in a Global World: Production Relocation, Innovation and Industrial decline. California Review Management, vol. 49, n. 1, 2006, p. 101-122.

BATTAR, Joseph. China's Outward Foreign Direct Investment. FIAS, World Bank Group, 2007.

BRAUTIGAM, Deborah; XIAOYANG, Tang; XIA, Ying. What Kinds of Chinese 'Geese” Are Flying to Africa? Evidence from Chinese Manufacturing Firms. Journal of African Economics, v. 27, n. 1, ago., 2018, p. 29-51.

CANTWELL, John. A survey of theories of international production. In: PITELIS, Christos; SUGDEN, Roger. (eds.). The Nature of the Transnational Firm. Londres: Routledge, 1991. 
CARMODY, Pádraig. The Geopolitics and Economics of BRICS' Resource and Market Access in Southern Africa: Ainding Development or Creating Dependency? Jounal of Southern African Studies, v. 43, n. 5, 2017, p. 863-877.

EISENMAN, Joshua; SHINN, David H. China and Africa. In: SHANGUHYIA, Martin S.; FALOLA, Toyin. (eds.). The Palgrave Handbook of African Colinal and Postcolonial History. New York: Palgrave Macmillan, 2018, p. 839-842.

FOWLER, Joshua. China's Multi-Faceted Economic Development Strategy in East Africa. Orbis, v. 63, n. 2, 2019, p. 172-186.

FURTADO, Celso. Subdesenvolvimento e estagnação na América Latina. Rio de Janeiro: Civilização Brasileira, 1968.

FURTADO, Celso. O Brasil não se Desenvolveu, Modernizou-se. In: MOTTA, Lourenço Dantas (org). História Vivida. Volume 3. São Paulo, OESP, 1981.

GRIPS Development Forum. Diversifying PRSP. Box of Flying Geese Model. Johanesburgo, set., 2002. Disponível em: <http://www.grips.ac.jp/forum/module/prsp/FGeese.htm>. Acesso em: 10 dez. 2020.

HAGE, José Alexandre Altahyde. A Teoria da Dependência: Uma Contribuição aos Estudos de Relações Internacionais. Revista Política Hoje, v. 22, n. 1, 2013, p. 106-136.

GADALLAH, Yasser M. An Analysis of the Evolution of Sino-Egyptian Economic Relations. In: NORESH, Niv (ed.). Toward well-oiled Relations? New York: Palgrave Macmillan, 2016, p. 94114 .

IGHOBOR, Kingsley. China in the Heart of Africa. African Renewal, january 2013. Disponível em: <https://www.un.org/africarenewal/magazine/january-2013/china-heart-africa >. Acesso em: 20 ago. 2020.

KIYOTA, Kozo. Industrial Upgrading in a Multiple-cone Hecksher-Ohlin Model: The Flying Geese Patterns of Industrial Development. Review of Development Economics, vol. 18, n. 1, p. 177193, 2014.

KOBYLINSKI, Katarina. Chinese investment in Africa: checking the facts and figures. Association for International Affairs, jul. 2012. Disponível em: <http://www.amo.cz/wpcontent/uploads/2015/11/amocz-BP-2012-7.pdf >. Acesso em: 12 ago. 2020.

KOJIMA, Kiyoshi. The "flying geese" model of Asian economic development: origin, theoretical extensions, and regional policy implications. Jounal of Asian Economics, v. 11, 2000, p. 375401.

KUMAGAI, Satoru. A Journey Through the Secret History of Flying Geese Model. IDE Discussion Paper, n. 158, jun. 2008. Disponível em:

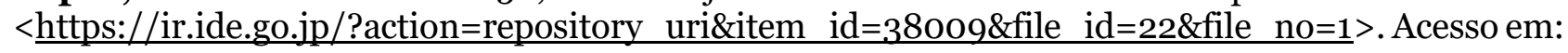
12 ago. 2020.

LAHTINEN, Anja. China's Diplomacy and Economic Activities in Africa. Cham, Switerland: Palgrave Macmillan, 2018.

LI, Shubo. Mediatized China-Africa Relations. Singapura: Palgrave Macmillan, 2017.

MARINI, Ruy Mauro. Dialética da Dependência: Uma Antologia da obra de Ruy Mauro Marini. Petrópolis: Vozes, 2000. 
MELLO, João Manuel Cardoso de. O Capitalismo Tardio. São Paulo: Brasiliense, 1988.

MEN, Jing; BARTON, Bejamin. China and the European Union in Africa: partners or competitors? Burlington, EUA: Ashgate Publishing, 2011.

MENDES, Ana Paula F.; BERTELLA, Mário A.; TEIXEIRA, Rudolph F. A. Industrialization in SubSaharan Africa and import substitution policy. Brazilian Journal of Political Economy, v. 34, n. 1, 2014, p. 120-138.

MELBER, Henning. China in Africa: A new partner or another imperialist power? Africa Spectrum, vol. 43, n. 3, 2008, p. 393-402.

MOFCOM. List of OECCZs that have pass the confirmation assessment. 2020. Disponível em: <http://fec.mofcom.gov.cn/article/jwjmhzq/articleo1.shtml>. Acesso em: 12 ago. 2020.

MORTIMORE, Michael. Flying Geese or sitting ducks? Transnational and industry in developing countries. CEPAL Review n. 51, dez. 1993, p. 15-34.

OBAMBA, Milton O. The Dragon's Deal. In: MIHUIT et al. (eds). Understanding Higher Education Internationalization. Roterdã: Sense Publishers, vol. 39, 2017, p. 163-165.

OKERE, Austine. Specialized Economic Zonez (SEZs) in Africa: Exporting Production, Performance, and Perils. Impakter, August 16, 2019. Disponível em: <https://impakter.com/specializedeconomic-zones-in-africa/>. Acesso em: 20 ago. 2020.

OLUWASEYI, Adetutu. Towards an appropriate regulatory enviroment for special economic zones in Nigeria. Dissertação de Mestrado em Direito. Universidade de Pretrória, 2016. Disponível em: <https://repository.up.ac.za/handle/2263/58738>. Acesso em 20 ago. 2020.

OKITA, Saburo. Special presentation: prospect of Pacific economies. Fourth Pacific Economic Cooperation Conference, Korea Development Institute: Seoul, abr./mai., 1985, p. 18-29.

PAIRAULT, Thierry. China in Africa: nests versus Special Economic Zones. HAL archivesouvertes Occasional Papers $\mathrm{n}^{0}$ 7, dec. 2018. Disponível em: <https://hal.archivesouvertes.fr/hal-01968812/document>. Acesso em 12 ago. 2020.

PREBISCH, Raúl. El desarrollo económico de la América Latina y algunos de sus principales problemas. Desarrollo Económico, v. 26, n. 103, out/dez., 1986, p. 479-502.

SANTOS, Theotonio dos. The Structure of Dependence. The American Economic Review, v. 60, n. 2, mai. 1970, p. 231-236.

SONG, Hong. Chinese Private Direct Investment and Overseas Chinese Network in Africa. China \& World Economy, v. 19, n. 4, p. 109-26, 2011.

THORBORG, Marina. From White Elephants to Flying Geese: China in Africa, a New Model for Development or More of the Same. In: KIM, Young-Chan (ed.). China and Africa: A New Paradigm of Global Business. Cham, Switzerland: Palgrave Macmillan, 2017.

UNCTAD. Asian Foreign Direct Investment in Africa: Towards a New Era of Cooperation Among Developing Countries. New York: United Nations, 2007.

WANG. Mark Yaolin. The motivations behind China's government-initiated industrial investment overseas. Pacific Affairs, v. 75, n. 2, p. 187-206, 2002. 
XIAOYANG, Tang. 8 Geese Flying to Ghana? A Case Study of the Impact of Chinese Investments on Africa's Manufacturing Sector. Journal of Contemporary China, v. 27, n. 114, 2018.

ZENG, Douglas. Special Economic Zones: Lessons from the Global Experience. PEDL Synthesis Paper Series, $\quad$ n. $1, \quad 2019 . \quad$ Disponível em: $<$ https://pedl.cepr.org/sites/default/files/PEDL Synthesis Paper Piece No 1 o.pdf $>$. Acesso em 19 ago. 2020. 